\title{
El sistema de crédito cooperativo brasileño y la identidad cooperativa: la necesidad de vigilancia permanente de los valores del cooperativismo para la sostenibilidad del modelo
}

(Brazilian system credit cooperative and cooperative identity: the need for permanent surveillance cooperative values for sustainable model)

José Eduardo de Miranda1

Director General de Kheíron Educacional

«No existen científicos «inventores» del cooperativismo, es sencillamente (y esa es su mayor grandeza) una formulación del ser humano (el «buen salvaje») no envilecido por la deshumanizada relación competitiva de una sociedad económicamente insolidaria».

Javier Divar Garteiz-Aurrecoa²

Sumario: Introducción. I. Para que no se olvide la génesis del cooperativismo: el diferencial de la sociedad cooperativa. II. Fuentes históricas del cooperativismo de crédito en el mundo. III. El sistema de crédito cooperativo, el concepto de cooperativa de crédito y el ámbito de su actuación según la ley brasileña. IV. Las particularidades del sistema brasileño de crédito cooperativo. V. El sistema de crédito cooperativo brasileño y la actividad financiera: entre la similitud del ejercicio bancario y el riesgo de la pérdida del paradigma originario por la afectación del principio de adhesión libre y voluntaria. VI. A título de conclusión: sistema de crédito cooperativo, identidad cooperativa y la ne-

1 Correo electrónico: jemiranda@mirandacorrealima.com

2 DIVAR GARTEIZ-AURRECOA, Javier. Filosofía de la cooperación. In Deusto Estudios Cooperativos. N.1. Bilbao: Universidad de Deusto, 2012, p. 34. 
cesidad de vigilancia permanente de los valores cooperativos para la sostenibilidad del modelo. VII. Bibliografía.

Resumen: El sistema de crédito cooperativo es una herramienta de prestación de servicios financieros a los miembros y terceros. La constitución de una sociedad cooperativa en Brasil, independiente de integrar en sus estatutos el marco de valores y principios Cooperativos, sigue las normas definidas por el Banco Central, y por el Sistema Financiero Nacional, viabilizando la ruptura del principio de la adhesión libre y voluntaria. La sostenibilidad del sistema de crédito está subrogada a la vigilancia permanente de la identidad cooperativa, a través de la prevalencia de sus valores y principios.

Palabras clave: Sistema de crédito cooperativo brasileño. Identidad. Sostenibilidad.

Abstract: The cooperative credit system is a tool for providing financial services to members and third parties. The establishment of a cooperative society in Brazil, independent of integration in their statutes under cooperative values and principles, follow the rules set by the Central Bank, and the National Financial System, making possible breach of the principle of free membership and voluntary. The sustainability of the credit system is subrogated to the permanent monitoring of the cooperative identity, through the prevalence of its values and principles.

Key words: Brazilian cooperative credit system. Identity. Sustainability 


\section{Introducción}

Actualmente, el sistema de crédito cooperativo es uno de los fenómenos más peculiares existentes dentro de los sistemas financieros del mundo, basados en un régimen de libre mercado y capitalista plenamente evolucionado ${ }^{3}$.

Por así decir, la «economía de escala de los servicios comunes, conseguidos a través de la ordenación de los sistemas, es la alternativa más adecuada para el funcionamiento del Cooperativismo de crédito, ya que posee marco regulatorio y naturaleza propios» ${ }^{4}$ que orientan su constitución y desarrollo dentro del escenario socio-económico-jurídico brasileño.

Las cooperativas de crédito, independiente de su naturaleza, perfil existencial y ejercicio, surgen como entidades financieras que materializan la prestación de servicios comunes a los bancos, entidades de aspecto propio y distinto de la sociedad cooperativa.

Dentro de este marco objetivo que delimita el tipo de actividad, las sociedades cooperativas brasileñas siguen las normas definidas para las entidades financieras, y tienen en su contexto formativo una interferencia que puede macular su génesis originaria, y altercar su propia identidad.

De este modo, el presente trabajo tiene el objetivo de examinar las peculiaridades del sistema de crédito cooperativo en Brasil, analizando las principales reglas que orientan su proceso de constitución, delimitando la pauta específica que compromete su identidad.

Para ello, además de un recorrido por el surgimiento de las cooperativas de crédito en el mundo, se adopta el método deductivo, y se utiliza la investigación directa e indirecta.

\section{Para que no se olvide la génesis del cooperativismo: el diferencial de la sociedad cooperativa}

La incursión analítica a través de cualquiera de las ramas del sistema cooperativo presentes en las diferentes legislaciones del globo requiere el conocimiento sobre las características básicas y originales del

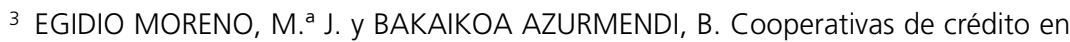
la comunidad autónoma del país vasco y navarra: retos de futuro. San Sebastián: GEZKI, 1999, p 11.

4 PAGNUSSATT, Alcenor. Guia do cooperativismo de crédito. Organização, governaça e políticas corporativas. Porto Alegre: Sagra Luzzatto, 2004, p. 
Cooperativismo, así como la comprensión de la idea motivadora de sus pioneros. En este sentido, es importante recordar que:

«la tendencia social cooperativa es expresión positiva y muy concreta de la incoercible reivindicación libertaria del ser humano, por lo que, insistimos, así como en el problema de las nuevas relaciones económicas, la Cooperación libre implica la abolición del poder autocrático del patrón, o sea del capital, a cuyo servicio está el hombre actualmente, así también en el problema de las relaciones políticas la Cooperación implica la progresiva abolición, o extinción, de las formas autoritarias de poder fundado en la fuerza o la violencia del mandatario». 5

No se puede rechazar, pues, la recíproca influencia de los hechos y de las opiniones en el desarrollo del propio sistema cooperativista, dado que este modelo no salió de la mente de un sabio o reformador, sino de las propias entrañas del pueblo ${ }^{6}$. Los esfuerzos personales, en muchos casos, son anteriores a la formulación de la doctrina y, las técnicas, resultantes de complicadas elucubraciones, han sido modificadas en presencia de valioso empirismo de quienes día a día se enfrentan a los problemas económicos y sociales de sus semejantes. Algunos de los más notables ideólogos de la cooperación han tratado de llevar a la práctica sus ideales y no pocos de quienes han iniciado su labor como hombres prácticos se interesaron, ya en el desarrollo de sus programas, por el contenido ideológico de las obras que producen tan provechosas transformaciones ${ }^{7}$.

Mucho es lo que se ha escrito sobre las tentativas de reacción de los trabajadores contra la opresión estatal y empresarial, tratando de resolver sus graves problemas socioeconómicos mediante asociaciones de carácter mutualista.

Sin embargo, no se puede olvidar que fue en el enredado conjunto de los más diversos tipos de resistencia a las secuelas del liberalismo económico donde las ideas cooperativas empezaron a ser construidas, recibiendo principalmente inspiración de la corriente liberal de los socialistas utópicos franceses e ingleses del siglo xIx. En ésta época, se generalizaba «el gran entusiasmo por la tradición de libertad de Des-

5 ARGUEIRA MIRANDA, M. A.: Hacia la comunidad cooperativa libre. 2. ${ }^{a}$ edición, Buenos Aires: Intercoop Editora Cooperativa Limitada, 1975, p. 15.

6 Véase en KESSELMAN, J: Sociedades cooperativas: Buenos Aires: Victor de Zavalia, 1979, p. 25; y GIDE, C.: El consumidor y el beneficio. La cooperación como programa económico y otros textos. Zaragoza: Aecoop, 1974, p. 53.

7 URIBE GARZON, C.: Bases del cooperativismo. Bogotá: Fondo Nacional Universitario, 1993, p. 61. 
cartes, confiándose en la posibilidad de acción de la voluntad humana sobre la evolución económica, con el fin de corregirla o reformarla. La «razón pensante» era considerada la única medida de todas las cosas y también la única en condiciones de descubrir las fallas de la organización económica y los remedios para corregirlas. Al mismo tiempo, el ambiente intelectual de los socialistas utópicos estaba impregnado de ideales de justicia y de fraternidad. La esperanza de una vuelta a la Naturaleza, a su vez, dejaba en evidencia la oposición de diversos autores a las consecuencias de la Revolución Industrial» ${ }^{8}$.

Para el hallazgo del punto básico de una visión histórica de la cooperación, es preciso reconocer el carácter fundamentalmente popular de las instituciones cooperativas.

Tanto en las formas embrionarias de la prehistoria cooperativa, cuando de manera casi espontánea, las gentes se unían para la satisfacción de las necesidades económicas que era imposible saciar individualmente por la escasez de los recursos personales, como en las manifestaciones de épocas posteriores, cuando ya se perfilaba el nuevo sistema, nacido para contrarrestar los abusos del individualismo expresado en la explotación del hombre por el hombre, las vinculaciones de la cooperación con los grupos populares aparecen con rasgos perfectamente definidos 9 .

En la historia de la humanidad, como en la naturaleza, se localizan, desde los comienzos, una infinidad de instituciones de ayuda mutua. En cuanto apareció sobre la faz de la tierra, el hombre se organizó en tribus cuyos miembros dependían, para su existencia, de sus estrechos lazos comunes; en los tiempos prehistóricos encontramos las primeras comunidades aldeanas basadas totalmente sobre prácticas de la ayuda mutua; la etapa siguiente fue la de la organización comunal en ciudades fortificadas, con organismos sociales complejos, cada uno de los cuales representaba una fuerte célula de ayuda mutua ${ }^{10}$.

Es indudable que los medios y las clases en que han surgido, y en que se han desarrollado, las cooperativas, se hallan relacionadas con todas las formas de asociación popular. En favor de éstas, aunque valiéndose de métodos que les son típicos, representan el mismo esfuerzo de defensa, de realce y de emancipación. Sin embargo, debiese subrayar que la diferencia de las otras formas de asociación popular es que

8 BENEVIDES PINHO, D. Evolución del pensamiento cooperativista. Buenos Aires: Intercoop Editora Cooperativa Limitada, 1987, pág. 11.

9 PREUSS, W. El cooperativismo en Israel y en el mundo. Tel-Aviv: Centro de Estudios Cooperativos y Laborales, 1966, p. 31.

10 URIBE GARZON, 1993, p. 14. 
las sociedades cooperativas son constituidas para perseguir un objetivo mediante una actividad económica organizada, a través de una empresa.

Para demostrar las ventajas de una cooperativa en relación a una asociación capitalista, Fauquet utiliza como ejemplo el modelo de la empresa lechera. Explica, pues, que la sociedad cooperativa no se complacerá con recoger, pura y simplemente, la leche entregada a sus socios. "Tendrá en cuenta, además, la calidad de la misma, su contenido de grasa, su pureza física y biológica, estado sanitario de las vacas lecheras, su selección, alimentación, buena apariencia de los establos, etc. ${ }^{11}$. A su vez, la lechería de naturaleza capitalista, que tenga las mismas preocupaciones, no logrará obtener de sus simples proveedores la colaboración disciplinada que la sociedad cooperativa recibe de sus miembros, teniendo en cuenta que éstas, al agruparse, ambicionan que su producción lechera se consolide dentro de las mejores condiciones, sostenida por un lazo moral de solidaridad que «eleva el nivel material de las clases populares y su nivel moral. Si vacilara en su obra moral, vacilaría igualmente en su finalidad económica» ${ }^{12}$.

Las cooperativas, salvo en el caso de algunos detractores aislados, han merecido el reconocimiento general de ser consideradas como formas de organización socioeconómica aptas para promover la activa participación y contribución de amplios sectores de la población, a los procesos de desarrollo.

Es necesario observarse que en otras condiciones y frente a políticas reservadas a beneficiar intereses monopólicos externos y consolidar privilegios existentes, «las cooperativas han demostrado su amplitud, para actuar, a través de la ayuda mutua y la solidaridad, como instrumentos eficaces de defensa de la economía de las capas medias y de los sectores populares» ${ }^{13}$.

Quizás por esto ha habido siempre, en el movimiento cooperativo, dos corrientes que corresponden a dos tendencias en lucha constante dentro de la naturaleza humana:

«Una de ellas, más bien positiva, busca en la Cooperación las ventajas inmediatamente realizables; la otra, más bien idealista, persigue en la Cooperación no lo que ella puede proporcionarnos, sino lo que

11 FAUQUET, G. El sector cooperativo. Buenos Aires: Intercoop Editora Cooperativa Limitada, 1973, p. 23.

12 FAUQUET, 1973, p. 28.

13 SCHUJMAN, L. Cooperativismo: desarrollo, participación, financiamiento, educación. Rosario: Ediciones Idelcoop, 1979, p. 53. 
puede prometernos. Son, por lo demás, inseparables y marchan juntas: Tales como Sancho Panza y Don Quijote» ${ }^{14}$.

Hoy por hoy, el sistema cooperativo es la herencia de la obra de numerosos pensadores que han trabajado sobre el propio terreno de los problemas económicos y sociales. Unos, verdaderos reformadores, han abandonado las realidades materiales del presente: son los ideólogos, los precursores; otros han buscado, más bien, la coordinación de esfuerzos, e incluso han procurado trazar nuevos caminos para la acción práctica del movimiento; son, desde el punto de vista teórico, los que podríamos llamar realizadores; pero lo más frecuente es que ellos sean, al mismo tiempo, los realizadores prácticos de los sistemas cooperativos ${ }^{15}$.

\section{Fuentes históricas del cooperativismo de crédito en el mundo}

No se quiere, aquí, promover una inmersión en el flujo de tiempo y espacio de todas las experiencias que han provocado influencia a la conformación de las cooperativas de crédito. También no se va hincar pie en el transcurso histórico de las cooperativas de crédito en Brasil. Sin embargo, y para la sustentación de la génesis identitaria, es importante anotar que influenciado por la Cooperativa de los Probos Pioneros de Rochdale nacida en Inglaterra, en el año de 1844, el cooperativismo de crédito surgió próximo del año de 1850, en el ámbito rural y urbano de Alemania, desarrollándose bajo el ejercicio teórico y práctico de Hermann Schulze Delitzsch, Fredeerico Guillermo Raiffeisen e Wilhelm Haas.

Inicialmente, las primeras sociedades cooperativas de crédito tenían funciones dirigidas únicamente a sus socios y «consistían esencialmente en facilitar créditos, mediante un sistema mutualista y con intereses reducidos a familias modestas, agricultores, pequeños artesanos y comerciantes, para evitar que se endeudaran con los usureros» ${ }^{16}$.

Las cooperativas de crédito de Schulze remontan al año de 1849 y fueron idealizadas por el magistrado Herman Schulze, como bancos populares establecidos en el seno de vida de los artesanos de la época. En líneas generales, las principales características de sus «bancos cooperativos» consistían en el hecho de que: i) no eran asociaciones de clase específica, permitiendo la participación de miembros de diferentes

14 GIDE, C. Cooperativismo. Bogotá: Publi-Coop, 1968, p. 23.

15 MLADENATZ, G. Historia de las doctrinas cooperativas. Buenos Aires: Intercoop Editora Cooperativa Limitada, 1969, p. 8.

16 EGIDIO MORENO, M. ${ }^{a}$ J. y BAKAIKOA AZURMENDI, 1999, p. 15. 
categorías económicas; ii) el capital social se constituía a través de cuotas partes de los miembros; iii) tenían un fondo de reserva no inferior a diez por ciento de capital constituido; iv) distribuían dividendos entre los asociados; y, v) los miembros tenían responsabilidad solidaria e ilimitada por las obligaciones sociales ${ }^{17}$. Los registros históricos demuestran que entre los años 1852 a 1855, Herman Schulze "fundó 7 cooperativas de crédito, difundiendo sus ideas por todo el país, llegando en 1861 a existir 340 cooperativas basadas en sus principios» ${ }^{18}$.

A su vez, las cooperativas de crédito de Raiffeisen fueron constituidas en la región de Heddesford, en el año de 1854, y seguían los principios cristianos de amor al ajeno.

De entre las principales particularidades de éstas cooperativas de crédito, se puede destacar: i) la responsabilidad solidaria e ilimitada de sus miembros cuanto a los negocios celebrados por la sociedad; ii) el gran valor a los conceptos morales de los miembros; iii) los dirigentes no recibían remuneración ${ }^{19}$.

De otra forma, Wilhelm Haas promueve una fusión de los modelos precedentes, y trabaja en el sentido de provocar la independencia de los agricultores.

En este sentido, Haas defiende que las cooperativas de crédito pueden obtener, a través de la autoayuda, la expansión del crédito agrícola, facilitando la compra de herramientas, de máquinas, la contratación de seguros y la disminución del precio de los productos. Diferente de sus sucesores, Haas no tenía preocupación por los atributos éticos y morales de los miembros, de manera que solo se preocupaba con las cuestiones relacionadas a la propia cooperativa de crédito ${ }^{20}$.

Teniendo en cuenta que Alemania, mismo que de forma tardía, experimentó el fenómeno de la Revolución Industrial, resulta correcto decir que las cooperativas de crédito surgieron frente a los abusos del control de poder, y tenían el propósito de cumplir un papel social de gran importancia, al evitar que los ciudadanos se vieran obligados a acudir a los usureros ${ }^{21}$.

Bajo este aspecto, Bélgica conoce el sistema de crédito cooperativo a partir del año de 1890, a través del trabajo del cura Mellaert, lo cual, p. 89.

17 BENEVIDES PINHO, D. Economia e cooperativismo. São Paulo: Saraiva, 1977,

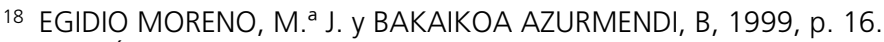

19 THENÓRIO FILHO, Luiz Dias. Pelos caminhos do cooperativismo: com destino ao crédito mútuo. São Paulo: CECRESP, 1999, p. 40.

20 BENEVIDES PINHO, 1977, p. 95.

21 EGIDIO MORENO, M. ${ }^{a}$ J. y BAKAIKOA AZURMENDI, B, 1999, p. 17. 
con el apoyo de políticos, fundó la Liga Campesina de Lovaina. Después se crearon las Cooperativas de Depósitos y Préstamos, unificadas en una Caja Central que en el año de 1935 recibió el nombre de Cajas Raiffeisen ${ }^{22}$.

Lo que resulta sugestivo es que en la época del surgimiento de las cooperativas de crédito, los créditos eran otorgados sobre la base de la confianza y de carácter muy personalista.

Además de ello, es oportuno subrayar que «algunas de estas cooperativas se han desarrollado y evolucionado hasta la fecha actual, constituyendo en muchos países de nuestro entorno grandes grupos financieros» ${ }^{23}$.

\section{El sistema de crédito cooperativo, el concepto de cooperativa de crédito y el ámbito de su actuación según la ley brasileña}

El sistema de crédito cooperativo, dentro del universo del propio Cooperativismo, se revela como una herramienta de doble sentido: el primero, es el de retener los ahorros de una determinada región, y, el segundo, viabilizar la destinación de recursos económicos a costes menores, para emprendimientos derivados de pequeñas inversiones que establezcan identidad con su local de inserción ${ }^{24}$.

A par de ello, se tiene la lógica originaria de que todas las inversiones de los miembros en las cooperativas acaban retornando a su entorno, a través de emprestamos a las personas de su entorno. Es así que el sistema de crédito Cooperativo revela su papel.

Bajo esta perspectiva, se debe asignar que, inicialmente, la creación de sociedades cooperativas de crédito suponía un ejercicio para el desarrollo de las actividades cooperativas a través de un sistema de financiación propio.

Sin embargo, aunque siguen constituyendo el pilar de las actividades más diversificadas en los distintos escenarios sociopolíticos, «las cooperativas de crédito han evolucionado hacia la banca universal, ofreciendo a sus miembros y clientes toda la gama de servicios financieros y de productos parabancarios existentes en el mercado» ${ }^{25}$.

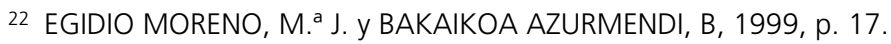

23 Ibid, p. 15.

24 SOUZA, Roberta de Castro. Difusão da inovação e das redes interorganizacionais no agronegócio de exportação de frutas in natura. In: AMATO NETO, João (org.). Redes entre organizações: domínio do conhecimento e da eficácia operacional. São Paulo: Atlas, 2005.

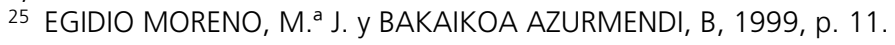


En este sentido, es corriente el entendimiento de que las cooperativas de crédito son entidades de aspecto financieros que se constituyen bajo el marco normativo del Cooperativismo, teniendo como objeto primordial la prestación de servicios de intermediación financiera a sus miembros.

Dentro del orden legal brasileña, la norma del artículo $2^{\circ}$, de la Ley Complementar n. ${ }^{\circ} 130$, de 17 de abril de 2009, define que las cooperativas de crédito se destinan exclusivamente "a proveer, por medio de la mutualidad, la prestación de servicios financieros a sus asociados, siéndoles asegurado el acceso a los instrumentos del mercado financiero» ${ }^{26}$.

Siguiendo esta orientación, el texto legal brasileño determina, por el párrafo primero, del artículo $2^{\circ}$, que:

«la captación de recursos y la concesión de créditos y garantías deben ser restrictas a sus asociados, reservadas las operaciones realizadas con otras instituciones financieras y los recursos obtenidos de personas jurídicas, en carácter eventual, a tazas favorecidas o libres de remuneración ${ }^{27}$.

No obstante, las cooperativas de crédito pueden prestar servicios múltiplos de aspecto financiero a no miembros, desde que observados siempre aquellos que la ley destina exclusivamente a los socios.

Del mismo modo, la legislación en Brasil es muy precisa en determinar, por la expresión del párrafo tercero del artículo $2^{\circ}$, que:

«la concesión de créditos y garantías a integrantes de los órganos estatutarios así como a personas físicas o jurídicas que con ellos mantengan relaciones de parentesco o negocio, debe observar procedimientos de aprobación y control idénticos a los dispensados a las demás operaciones de crédito!» 28 .

En la medida que el ámbito de actuación de las cooperativas de crédito no puede ultrapasar el límite territorial de los municipios descritos en el estatuto social, todo su ejercicio está sometido a las normas emitidas por el Consejo Monetario Nacional y por el Banco Central de Brasil ${ }^{29}$, además de las disposiciones de la Ley 4.595/1964, y de la ley general de cooperativas, Ley 5.764/1971.

26 MIRANDA, José Eduardo de; DA SILVA GALHARDO, José Henrique y LINS VIEIRA, Paulo Gonçalves. Regime jurídico da sociedade cooperativa. Curitiba: Juruá, 2013, p. 53.

27 Ibid., p. 54.

28 BRASIL. Lei Complementar n. ${ }^{130}$, de 17 de abril de 2009. Disponible en el «http://www.planalto.gov.br/CCIVIL_03/leis/LCP/Lcp130.htm», Acceso en 30/may/2015.

${ }_{29}$ Conforme determina el párrafo primero, de artículo $1^{\circ}$, de la Ley Complementar $130 / 2009$. 
El desarrollo de las actividades de las sociedades cooperativas de crédito es muy similar al ejercicio de las entidades bancarias, de manera que prestan los mismos servicios que deben ser elaborados según el marco de valores y principios del cooperativismo enunciados por la Alianza Cooperativa Internacional en 1995, en Manchester, para que no pierda su identidad y naturaleza propias. En este sentido:

«la nueva formulación de los principios cooperativos (asociada a la declaración de los valores) refleja la señal de alarma para que los hombres del Cooperativismo se percaten de las exigencias, de las ideologías, de los objetivos, de las causas y de los fines del movimiento cooperativo ${ }^{30}$ ».

De esta manera el universo cooperativista mantiente fijo e inmutable el sentimiento de que "Manchester ha llamado al Cooperativismo para rescatar su verdadero quehacer, cuyo fin supera el de intentar promover algo más que los intereses de los miembros individuales que componen una cooperativa» ${ }^{31}$.

\section{Las particularidades del sistema brasileño de crédito cooperativo}

Siguiendo la dinámica organizacional definida por el artículo $6^{\circ}$, de la ley general de cooperativas de Brasil, Ley 4.595/1964, el sistema de crédito cooperativo puede conformarse como cooperativa singular; central, federación o cooperativas de segundo grado; y, confederaciones o cooperativas de tercero grado.

En este sentido, y siguiendo el rigor de la legislación se puede decir que las cooperativas singulares son todas las cooperativas constituidas por un número mínimo de veinte miembros y tienen el objetivo de prestar servicios directos a sus asociados ${ }^{32}$.

De otra forma, las cooperativas centrales, federación o cooperativas de segundo grado, son formadas por un número mínimo de tres cooperativas singulares, y tienen el objetivo de organizar, en una escala más amplia, las operaciones realizadas por sus miembros, optimizando la utilización recíproca de los servicios de ambas 33 .

30 MIRANDA, José Eduardo de. De la crisis de identidad al rescate de la génesis del cooperativismo. Madrid: Dykinson, 2012, p. 53.

31 Ibid., p. 53.

32 MIRANDA, José Eduardo de; DA SILVA GALHARDO, José Henrique y LINS VIEIRA, Paulo Gonçalves, 2013, p. 65.

33 MIRANDA, José Eduardo de; DA SILVA GALHARDO, José Henrique y LINS VIEIRA, Paulo Gonçalves, 2013, p. 65. 
Ya, las cooperativas de crédito de tercer grado, o confederaciones de cooperativas, son constituidas por un número no inferior a tres cooperativas de segundo grado, y su desarrollo se concentra en la promoción de la armonía, supervisión e integración operacional, financiera, estatutaria y tecnológica de las asociadas ${ }^{34}$.

Mirando hacia dentro de su estructura, hoy por hoy el sistema de crédito cooperativo brasileño posee ${ }^{35}$ :

- Cuatro sistemas de cooperativas de crédito de tercer grado: la CONFESOL, o Confederación de las Cooperativas de Crédito Rural con Interacción Solidaria; la SICOOB, o Confederación Interprovincial de las Cooperativas Ligadas al Sicoob; SICREDI, o Confederación Interprovincial de las Cooperativas Ligadas al Sicredi; y, UNICRED DE BRASIL, o Confederación Nacional de las Cooperativas Centrales Unicred's;

- Seis sistemas de cooperativas de crédito de segundo grado: la CECOOPES, o Central de las Cooperativas de Economía y Crédito Mutuo de la Provincia del Espírito Santo; la CECRED, o Central de las Cooperativas de Crédito Urbano; CECRERS, o Central de las Cooperativas de Crédito Mutuo del Rio Grande; CREDISIS, o Cooperativa Central de Crédito Noroeste Brasileño; UNICRED CENTRAL NORTE Y NORDESTE, o Cooperativa Central de Crédito del Norte/Nordeste; UNIPRIME CENTRAL, o Central Interprovincial de Cooperativas de Crédito;

- Todas las cooperativas singulares, de primer grado, no filiadas a las centrales.

\section{El sistema de crédito cooperativo brasileño y la actividad financiera: entre la similitud del ejercicio bancario y el riesgo de la pérdida del paradigma originario por la afectación del principio de adhesión libre y voluntaria}

Del modo que es peculiar a su propia actividad, el sistema de crédito cooperativo materializase como un mecanismo de prestación de servicios financieros a sus miembros, y de forma limitada, para personas externas al cuadro de asociados, siempre buscando optimizar el

34 Ibid., p. 65.

35 Informaciones disponibles en el Fondo Garantizador del Cooperativismo de Crédito, disponible en el «http://www.fgcoop.coop.br/o-sistema-nacional-de-credito-cooperativo-sncc-». 
atendimiento de sus respectivas necesidades de crédito, ahorro y demás servicios. En este sentido, encuentra-se el entendimiento de que:

«El objetivo de una cooperativa de crédito es desarrollar programas de asistencia financiera y de prestación de servicios a sus cooperados, con la finalidad de ofrecer adecuado atendimiento as sus necesidades de crédito, contribuyendo para tornárselos independientes de otras instituciones financieras públicas y privadas ${ }^{36}$ ».

La realidad material que ofrece forma y hecho a su existencia, demuestra perfectamente que el sistema de crédito cooperativo brasileño, por el propio objeto de su formación, encuadrase definitivamente dentro del contexto macro de las entidades financieras, resguardan la «calidad» de banco, y, por ello, están sometidas a la fiscalización de los órganos estatales congéneres a su fin, en Brasil el Banco Central y el Consejo Monetario Nacional.

En éste sentido, no se puede despreciar que el artículo 17, de la Ley 4.595, de 31 de diciembre de 1964, define que las instituciones financieras son las personas jurídicas públicas o privadas que tengan como actividad principal «o accesoria la coleta, cosecha, intermediación o aplicación de recursos financieros propios o de terceros, en moneda corriente o extranjera, y la custodias de valor de propiedad o terceros ${ }^{37}$.

Dentro del contexto de definición de las instituciones financieras, y en el ejercicio de correlación de las actividades desarrolladas en el ámbito del sistema de crédito cooperativo brasileño, es importante subrayar que las cooperativas de crédito son, en la esencia, instituciones financieras que prestan servicios de este aspecto a sus miembros y terceros.

Para oprimir eventual duda respecto a la similitud o identidad entre las cooperativas y las instituciones financieras, llamase la atención al hecho de que en la medida que el artículo primero, de la Ley Complementar 130/2009, de las cooperativas de crédito brasileñas, determina que las instituciones financieras constituidas bajo la forma de cooperativas de crédito deben someterse a la legislación específica del Sistema Financiero de Brasil, su párrafo primero, deja absolutamente claro que «las competencias legales del Consejo Monetario Nacional y del Banco

36 ETGETO, Anderson Augusto y otros. Os princípios do cooperativismo e as cooperativas de crédito no Brasil. Maringa Management: Revista de Ciências Empresariais, v. 2, n. 1, p. 7-19, jan. /jun. 2005. Disponible en «http://www.maringamanagement. com.br/novo/index.php/ojs/\%20article/\%20viewFile/30/15», acceso in 28/may/2015.

37 BRASIL. Lei 4.595, de 31 de dezembro de 1964. Disponible en el « http://www. planalto.gov.br/CCivil_03/leis/L4595.htm», acceso en 27/may/2015. 
Central de Brasil en relación a las instituciones financieras son aplicadas a las cooperativas de crédito» ${ }^{38}$.

Bajo esta configuración, las sociedades cooperativas de crédito brasileñas, en el ejercicio de las actividades financieras similares a las actividades bancarias, están abiertas a la interposición fiscalizadora externa, ajena a su cuadro de miembros y a los preceptos de sus estatutos, como bien determina el artículo 12, de la Ley Complementar 130/2009:

"Art. 12 El Consejo Monetario Nacional, en el ejercicio de las competencias que le son atribuidas por la legislación que rige el Sistema financiero Nacional, podrá disponer, incluso, sobre las siguientes materias:

I.- requisitos que deberán ser atendidos previamente a la constitución o transformación de las cooperativas de crédito, con vista al respectivo proceso de autorización a cargo de Banco Central de Brasil;

II.- condiciones que deberán ser observadas en la formación del cuadro de asociados y en la celebración de contractos con otras instituciones;

III.- tipos de actividades que deberán ser desarrolladas y de instrumentos financieros pasibles de utilización;

IV.- fundos garantizadores, inclusive la vinculación de cooperativas de crédito a tales fundos;

V.- actividades realizadas por entidades de cualquier naturaleza, que tengan por objetivo ejercer, con relación a un grupo de cooperativas de crédito, supervisión, control, auditoria, gestión o ejecución en mayor escala de sus funciones operacionales;

VI.- Vinculación a entidades que ejerzan, en la forma de la reglamentación, actividades de supervisión, control y auditoria de cooperativas de crédito;

VII.- condiciones de participación societaria en otras entidades, incluso de naturaleza no cooperativa, con vistas al atendimiento de los propósitos complementares, en el interese del cuadro social;

VIII.- requisitos adicionales al ejercicio de la facultad de que trata el artículo $9^{\circ}$ de esta ley complementar» ${ }^{39}$.

Integrada a la ordenación general destinada a las entidades que totalizan el sistema financiero nacional brasileño, las sociedades cooperativas de crédito están completamente sometidas a las reglas destinadas a los bancos, y permiten, incluso, la posibilidad de interferencia ajena

38 BRASIL. Lei Complementar n. ${ }^{\circ}$ 130, de 17 de abril de 2009.

39 Ibid. 
en el orden de su ejercicio, desde el acto de constitución, definición y desarrollo de las propias actividades.

Hay que decirse, y esto fluye de la ley, que la peculiaridad normativa de sistema de crédito cooperativo brasileño afecta las cooperativas de crédito de Brasil con el peligro de la contaminación del paradigma originario.

Esto, muy lejos de una percepción emocional, se observa a partir de la extensión de las pautas legales, determinantes, máxima, de la quiebra de la subjetividad inherente a la naturaleza de la cooperativa, a su ejercicio, y al Cooperativismo como un todo.

Por así decir, es fundamental señalar que la subjetividad surge a partir del vínculo que aproxima a los miembros con interés de reunirse en cooperativa, y externalizase en el flujo existencial de la propia sociedad cooperativa, materializado bajo la ordenación de los valores y principios del Cooperativismo, que deben estar presentes no solo en los estatutos, per en toda órbita de la relación entre los miembros, de estos con la cooperativa, y de todos con el mundo.

De esta forma, y no obstante las tipologías formales de los estatutos sociales de las cooperativa de crédito brasileñas, no se puede omitir que el inciso segundo, del artículo 12, de la Ley Complementar 130/2009 hiere el principio de adhesión libre y voluntaria, pues el Estado, a través del Sistema Financiero y del Banco Central, están legitimado a definir las condiciones que deberán ser observadas en la formación del cuadro de asociados y en la celebración de contractos con otras instituciones ${ }^{40}$.

Aquí, se confirma el riesgo de pérdida del paradigma originario, una vez que en el intuito de desarrollar actividades propias de bancos, el sistema cooperativo de crédito abre un hueco en la pilastra axio-principiológica de la cooperatividad, y permite que su proceso de conformación coincide con la regla mayor definida por la Alianza Cooperativa Internacional de que las cooperativas son asociaciones de personas unidas de forma voluntaria para satisfacer sus necesidades y aspiraciones económicas, sociales y culturales en común, mediante una empresa de propiedad conjunta y gestión democrática ${ }^{41}$.

En la medida que el estado define condiciones para el cuadro de miembros, la voluntariedad queda sepultada, y el paradigma cooperacionista completamente roto, despreciado.

40 BRASIL. Lei Complementar n. ${ }^{\circ} 130$, de 17 de abril de 2009.

41 MIRANDA, José Eduardo de. La financiación de las sociedades cooperativas. In Boletín de la Asociación Internacional de Derecho Cooperativo. Universidad de Deusto, Bilbao, 2003, p. 232. 


\section{A título de conclusión: sistema de crédito cooperativo, identidad cooperativa y la necesidad de vigilancia permanente de los valores cooperativos para la sostenibilidad del modelo}

Dicho el anterior, se muestra oportuno rescatar la idea de que la palabra Cooperativismo puede ser trabajada bajo dos percepciones distintas: una, que aporta la noción de un sistema económico organizado que tiene la proposición de oprimir, o eliminar, las heridas derivadas de los excesos del capitalismo, y, otra, el universo de valores y principios que conforman un espíritu propio para regir la postura actitudinal y de comportamiento del hombre que integra el propio sistema económico organizado42.

Por esta línea, e independiente del modelo o rama de actuación de sus respectivos sistemas, el Cooperativismo debe «reafirmar la base común intelectual y moral en la que puede fundamentarse la unión de los cooperativistas de todas las naciones, de todas las escuelas y de todos los sectores del movimiento ${ }^{43}$.

Es forzoso, pues, tenerse en cuenta que la vigente formulación de los principios cooperativos «refleja la señal de alarma para que los hombres del Cooperativismo se percaten de las exigencias, de las ideologías, de los objetivos, de las causas y de los fines del movimiento cooperativo» ${ }^{44}$.

Los principios, y por supuesto, los valores cooperativos, bajo el aspecto representativo de un modelo de comportamiento y de la toma de decisiones, muestran la precipua particularidad del Cooperativismo, definen la distinción de la sociedad cooperativa respecto a los demás modelos asociativos y configuran los rasgos de la identidad cooperativa.

Revelase necesario, entonces, que el sistema de crédito cooperativo tenga presente que los principios cooperativos representan un marco común que sirve de base para el fortalecimiento de la identidad cooperativa, de forma que anime la comprensión, las actividades conjuntas y los horizontes de toda clase de entidad cooperativa ${ }^{45}$.

Para conferir sostenibilidad al sistema de crédito, e impedir el peligro de una crisis identitaria, deben, los miembros de las cooperativas de crédito, tener presente en su ejercicio que «no es suficiente pre-

42 FRANKE, Walmor. Direito das sociedades cooperativas. São Paulo: Saraiva, 1973, p. 1.

$43 \mathrm{ACl}$. Principios del cooperativismo in Texto integro del informe de la Alianza Cooperativa Internacional. ACl, 1966, p. 21 y 22.

44 MIRANDA, 2012, p. 53.

45 MIRANDA, 2012, p. 47. 
guntar si una cooperativa está siguiendo al pie de la letra un principio dado; es igualmente importante saber si está siguiendo el espíritu «si la visión que proporciona cada principio, individual y colectivamente, está arraigada en las actividades diarias de la cooperativa»46, en los procedimientos de constitución y mismo en la elección de sus miembros.

Hoy por hoy es sabido por todos la importancia del sistema de crédito cooperativo para conferir arrimo a los procesos de desarrollo de las sociedades y del hombre. Sin embargo, no se puede desprestigiar la preponderancia de los valores y principios cooperativos para la disposición de la identidad cooperativa, inseparable del Cooperativismo y esencial a la sostenibilidad de sus respectivos sistemas, incluso el de crédito.

Por ello, es determinante tenerse en relieve que no se puede ofuscar un principio, pena de oprimirse a todos y sepultarse la identidad.

\section{Bibliografía}

ACl: «Principios del cooperativismo», Texto íntegro del informe de la Alianza Cooperativa Internacional, $\mathrm{ACl}, 1966$.

AMATO NETO, J. (org.): Redes entre organizações: domínio do conhecimento e da eficácia operacional, São Paulo, Atlas, 2005.

ARGUEIRA MIRANDA, M. A.: Hacia la comunidad cooperativa libre, 2. a edición, Buenos Aires, Intercoop Editora Cooperativa Limitada, 1975.

BENEVIDES PINHO, D.: Evolución del pensamiento cooperativista, Buenos Aires, Intercoop Editora Cooperativa Limitada, 1987.

BENEVIDES PINHO, D.: Economia e cooperativismo, São Paulo, Saraiva, 1977.

BRASIL: Lei Complementar n. ${ }^{\circ} 130$, de 17 de abril de 2009. Disponible en «http://www.planalto.gov.br/CCIVIL_03/leis/LCP/Lcp130.htm», Acceso en 30/may/2015.

DIVAR GARTEIZ-AURRECOA, J.: «Filosofía de la cooperación», Deusto Estudios Cooperativos, núm. 1. Bilbao, Universidad de Deusto, 2012.

EGIDIO MORENO, M. ${ }^{\text {a }}$ J. y BAKAIKOA AZURMENDI, B.: Cooperativas de crédito en la comunidad autónoma del país vasco y navarra: retos de futuro, GEZKI, 1999.

ETGETO, A. A.: «Os princípios do cooperativismo e as cooperativas de crédito no Brasil», Maringa Management:Revista de Ciências Empresariais, v. 2, n.1, p. 7-19, jan. /jun. 2005. Disponible in «http://www.maringamanagement.com.br/novo/index.php/ojs/\%20article/\%20viewFile/30/15», aceso in 28/may/2015.

$46 \mathrm{ACl}, 1996$, p. 45.

Boletín de la Asociación Internacional de Derecho Cooperativo ISSN: 1134-993X • ISSN-e: 2386-4893, Núm. 49/2015, Bilbao, págs. 65-82 
FAUQUET, G.: El sector cooperativo, Buenos Aires, Intercoop Editora Cooperativa Limitada, 1973.

FRANKE, W.: Direito das sociedades cooperativas, São Paulo, Saraiva, 1973.

GIDE, C.: El consumidor y el beneficio. La cooperación como programa económico y otros textos, Zaragoza, AECOOP, 1974.

GIDE, C.: Cooperativismo, Bogotá, Publi-Coop, 1968.

KESSELMAN, J.: Sociedades cooperativas, Buenos Aires, 1979.

MLADENATZ, G.: Historia de las doctrinas cooperativas, Buenos Aires, Intercoop Editora Cooperativa Limitada, 1969.

PREUSS, W.: El cooperativismo en Israel y en el mundo, Tel-Aviv, Centro de Estudios Cooperativos y Laborales, 1966.

URIBE GARZON, C.: Bases del cooperativismo, Bogot, Fondo Nacional Universitario, 1993.

MIRANDA, J.E.: "La financiación de las sociedades cooperativas», Boletín de la Asociación Internacional de Derecho Cooperativo. Universidad de Deusto, Bilbao, 2003.

MIRANDA, J.E.: De la crisis de identidad al rescate de la génesis del cooperativismo, Madrid: Dykinson, 2012.

MIRANDA, J. E.; DA SILVA GALHARDO, J.H.; LINS VIEIRA, P.G.: Regime jurídico da sociedade cooperativa, Curitiba, Juruá, 2013.

PAGNUSSATT, A.: Guia do cooperativismo de crédito. Organização, governaça e políticas corporativas, Porto Alegre, Sagra Luzzatto, 2004.

SCHUJMAN, L.: Cooperativismo: desarrollo, participación, financiamiento, educación, Rosario, Ediciones Idelcoop, 1979.

THENÓRIO FILHO, L.D.: Pelos caminhos do cooperativismo: com destino ao crédito mútuo, São Paulo, CECRESP, 1999. 